\title{
Effect of nandrolone decanoate on healing of experimentally induced radial nonunion in rabbits (Oryctolagus cuniculus)
}

\author{
Adrielly Dissenha ${ }^{1}$, Bruno Watanabe Minto, Karina Calciolari ${ }^{1}$, Laís Fernanda Sargi ${ }^{1}$, \\ Lismara Castro do Nascimento², Fabiana Del Lama Rocha ${ }^{1}$, Julián Andrés Sanjuán \\ Galindez ${ }^{1}$, Dayvid Vianêis Farias de Lucena ${ }^{1}$, Luis Gustavo Gosuen Gonçalves Dias ${ }^{1}$.
}

${ }^{1}$ Department of Veterinary Clinic and Surgery, Faculty of Agrarian and Veterinary Sciences, São Paulo State University, Jaboticabal, São Paulo, Brazil.

${ }^{2}$ Department of Morphology and Animal Physiology, Faculty of Agrarian and Veterinary Sciences, São Paulo State University, Jaboticabal, São Paulo, Brazil.

Correspondent autor: e-mail: brunowminto@gmail.com (BWM)

Acknowledgements: We thank Professor Dr. Alan Rodrigo Panosso, from the Department of Engineering and Exact Sciences for performing the static analyses of this study. We also thank Professor Dra. Silvana Martinez Baraldi Artoni and Professor Dra Lizandra Amoroso from the Department of Animal Morphology and Physiology, who allowed bone densitometry examinations.

Funding: This study was partly funded by the Coordenação de Aperfeiçoamento de Pessoal de Nível Superior (CAPES) of the Brazilian Government master's degree scholarship program. Author contributions: All authors contributed to the execution and design of the study as well as data analysis and interpretation. They were all involved in the writing or revision of the manuscript. All authors have approved the submitted version.

Conflicts of interest: The authors report no conflicts of interest. 
Effect of nandrolone decanoate on healing of experimentally induced radial nonunion

\section{ABSTRACT}

5 The aim of this study was to evaluate the effect of nandrolone decanoate (ND) on treatment of

6 bone nonunion in the radius of rabbits. Thirty-one, young adult, New Zealand White rabbits

7 (Oryctolagus cuniculus) were allocated to one of four groups: nandrolone males (NMG),

8 nandrolone females (NFG), placebo males (NPM), and placebo females (NPF). After bone

9 nonunion of a $10 \mathrm{~mm}$ ostectomy of the radius was confirmed (45 days after surgery), the

10 animals in the NMG and NFG groups received $10 \mathrm{mg} / \mathrm{kg}$ ND intramuscular once a week for

11 four weeks, while placebo groups received intramuscular $0.9 \% \mathrm{NaCl}$ solution. Radiographic,

12 histopathologic, and densitometric parameters (DXA) were used to compared groups.

13 Results: No significant differences were observed radiographically. However, ND groups

14 showed greater area $(\mathrm{P}=0.0258)$ and $\mathrm{BMC}(\mathrm{P}=0.0140)$ in the densitometric evaluation.

15 Histologically, the placebo group showed a predominance of primary bone tissue. Whereas,

16 lamellary organizations of secondary bone and the presence of fibrocartilage were found in the

17 ND group $(\mathrm{P}=0.006)$. In conclusion, ND promoted bone regeneration after the creation of a

18 large defect in the radius of rabbits.

19 Keywords: androgen, complication, healing, fracture.

\section{INTRODUCTION}

Delayed union and nonunion are common complications of osteosynthesis of long

23 bones in small animal practice. There are many factors resulting in nonunion, including 24 mechanical failures (excessive movement and/or the presence of large bone defects), and 25 damage to the vascularization of the fracture site $(1,2)$. A significant challenge in the treatment 
of nonunion is the bioactivation of the fracture environment and the filling of critical defects.

27 Classically, the use of bone grafts, bone marrow, and other activation factors has been used; despite treatment a significant proportion of nonunions fail to heal, especially in small dogs $(3,4)$.

30 Steroids are known to affect bone health and there has been increasing interest in the effect of hormones on bone regeneration. In vitro, osteoblastic cells may be stimulated by androgens. Several studies have looked at the use of anabolic steroids as adjuncts to bone repair. Although their mechanisms of action have not been elucidated, they are believed to stimulate osteoblastogenesis, inhibit the action of osteoclasts, and accelerate bone healing. Nandrolone decanoate (ND) is an anabolic steroid used, among other indications, for prevention and treatment of osteopenia as well as to increase bone mass. However, its use in vivo requires further investigation $(5,6)$. advancement, and the use of ND and autologous bone grafts, separately and in combination, have been compared; the results demonstrated that the concomitant use of ND and autologous bone grafts decreased the time to bone healing (6). Another study evaluated the use of ND in bone healing of tibial fractures induced in rabbits, and better osteoblastic and collagen proliferation were observed (7).

The aim of this study was to conduct radiographic, histopathologic, and densitometric evaluations on the use of ND in the treatment of, experimentally induced, unviable bone nonunion in rabbits. We hypothesized that the use of ND would correlate with faster and more effective bone regeneration. 

/ SP (protocol no. 019155). Thirty-one, young adult (160 to 170 days old), New Zealand White rabbits (Oryctolagus cuniculus) were used. They were entire and weighed $3.8 \mathrm{~kg}( \pm 0.3)$. Fifteen were males and 16 were females. Males and females were separately randomly allocated to either treatment or placebo groups, creating four groups: nandrolone males (NMG), nandrolone females (NFG), placebo males (NPM), and placebo females (NPF). One animal from NPM group died of unknown causes on the 75 th day.

\section{Experimental groups} once a week for four weeks. The PMG and PFG groups received intramuscular $0.9 \% \mathrm{NaCl}$ bone nonunion (45 days after the ostectomy). Radiographic, histopathologic, and densitometric parameters (DXA) were evaluated.

\section{Surgical procedure}

All rabbits underwent the same anesthetic protocol, were positioned in the right lateral decubitus position with the leg extended laterally, and prepared for sterile surgery. A cutaneous incision of approximately $2.5 \mathrm{~cm}$ was made in the craniomedial region of the radius. A $10 \mathrm{~mm}$ diaphyseal ostectomy of the radius was performed using an oscillatory saw. Local irrigation with $0.9 \% \mathrm{NaCl}$ solution was used to prevent overheating of the bone. The bone segment was removed with its periosteum, creating a $10 \mathrm{~mm}$ bone gap. Soft tissues were routinely sutured experience in general surgery and veterinary orthopedics. 
The animals received enrofloxacin $(10 \mathrm{mg} / \mathrm{kg}$ every 24 hours for 7 days

76

subcutaneously), tramadol hydrochloride ( $5 \mathrm{mg} / \mathrm{kg}$ every 12 hours for 3 days subcutaneously) and meloxicam ( $1 \mathrm{mg} / \mathrm{kg}$ single dose subcutaneously) postoperatively.

\section{Radiographic evaluation}

All rabbits underwent radiographic examination immediately after surgery and on 15, 30 , and 45 days postoperatively, until the nonunion was confirmed. ND and placebo treatments began when nonunion was confirmed. The animals were than radiographically evaluated at 60 , 75 , and 90 days postoperatively (15, 30 and 45 days after confirmation of the nonunion). A double-blind evaluation of the radiographic images was performed by two experienced evaluators.

Bone nonunion was scored before and after ND / placebo administration. Periosteal reaction (PR), volume of bone callus (VBC), and the quality of the bone bridge (QBB) between the fragments were the semi-quantitative parameters used for the evaluation - adapted from previous studies $(8,9)$. The means of the recorded values were used for analysis.

\section{Bone densitometry and histopathologic evaluation}

The animals were euthanized on the $90^{\text {th }}$ day postoperatively using midazolam (1 $\mathrm{mg} / \mathrm{kg}, \mathrm{IM}$ ) and propofol (dose-dependent) followed by an intravascular injection of $4 \mathrm{~mL}$ of potassium chloride to induce cardiac arrest. Immediately after euthanasia, bone densitometry examination of the dissected radius and ulna was performed. The bones were weighed and measured with a standard millimeter tape. The equipment was calibrated with the use of a phantom, with specific measures for bone analysis, and the bone was then placed on the table and an area of $3 \mathrm{~cm}$ was scanned. Bone mineral composition content $(\mathrm{g})$ and bone mineral density $\left(\mathrm{g} / \mathrm{cm}^{2}\right)$ measurements were obtained.

Afterwards, a segment of the radius was collected $10 \mathrm{~mm}$ proximally and $10 \mathrm{~mm}$ distally from the bone failure interfaces. Bone fragments were fixed in a $10 \%$ formalin solution 
buffered with sodium acid phosphate monohydrate and anhydrous disodium phosphate $(\mathrm{pH}$

101 7.4), decalcified, embedded in paraffin and stained by the Hematoxylin and Eosin (HE)

102 technique.

The histologic slides were evaluated for three factors: quality of bone neoformation, quantity of bone neoformation and type of bone tissue formed. Quality of bone neoformation, was scored on a scale $0=$ no periosteal reaction, $1=$ moderate periosteal response, $2=$ intense periosteal response, $3=$ disorganized neoformed bone tissue, $4=$ neoformed bone tissue with moderate organization, and $5=$ Neoformed bone tissue with advanced organization. Bone neoformation was scored on the scale where $0=$ no bone neoformation or it was not possible to assess, $1=$ mild bone neoformation, $2=$ mild $/$ moderate bone neoformation, $3=$ moderate bone neoformation, $4=$ moderate/intense bone neoformation, and $5=$ intense new bone

111 formation. The type of bone tissue was evaluated according to the scale where $1=$ prevalence

112 of primary bone tissue and 2 = prevalence of secondary bone tissue. (Table 1). All the 113 evaluations were performed by an experienced pathologist.

\section{Statistical analysis}

Statistical analyzes were performed using R Software version 3.6.3 (R Core Team,

2015). Statistical significance for all tests was considered when $\mathrm{P} \leq 0.05$.

118 Factorial in a randomized design, considering as fixed effects the factor A corresponding to

119 the sex (Male or Female), factor B treatment (Placebo or Nandrolone), factor interactions (sex $\times$

120 treatment), group errors, random animal effects, and residues corresponding to the model. This

121 ANOVA was performed after verification of mathematical assumptions (Shapiro-Wilk test and

122 Bartlett test), and Tukey's post-hoc was applied when ANOVA indicated a significant

123 difference between means. 
rank test, and Dunn's Multiple Comparison post-hoc was applied to the significant difference

between medians. The presence of cartilage and medullary spaces observed in the histologic

evaluation was compared between groups using Fisher's exact test.

\section{RESULTS}

Table 1. Median \pm IQR of radiographic evaluation in rabbits treated with ND versus placebo.

\begin{tabular}{cccccccccccc}
\hline & \multicolumn{2}{c}{ Placebo } & \multicolumn{1}{c}{ Nandrolone } & \multicolumn{1}{c}{ P-value } \\
\cline { 2 - 11 } & Male & Female & Male & Female & $\mathbf{G}$ & $\mathbf{T}$ & $\mathbf{G} \times \mathbf{T}$ & $\mathbf{M}$ & $\mathbf{T} \times \mathbf{M}$ & $\mathbf{G} \times \mathbf{M}$ & $\mathbf{G} \times \mathbf{T} \times \mathbf{M}$ \\
\hline PR & $2.0 \pm 0.25^{\mathrm{c}}$ & $3.0 \pm 1.0^{\mathrm{a}}$ & $2.0 \pm 0.5^{\mathrm{bc}}$ & $2.0 \pm 1.0^{\mathrm{ab}}$ & 0.157 & 0.853 & $<0.001$ & 0.643 & 0.961 & 0.027 & 0.141 \\
VBC & $2.0 \pm 1.0^{\mathrm{a}}$ & $1.0 \pm 0.0^{\mathrm{b}}$ & $3.0 \pm 2.0^{\mathrm{a}}$ & $2.0 \pm 1.0^{\mathrm{a}}$ & 0.152 & 0.157 & 0.004 & 0.456 & 0.124 & 0.249 & 0.243 \\
QBB & $2.0 \pm 2.0$ & $1.5 \pm 1.0$ & $3.0 \pm 2.0$ & $2.0 \pm 1.0$ & 0.160 & 0.152 & 0.293 & 0.262 & 0.619 & 0.292 & 0.791
\end{tabular}

$\mathrm{PR}=$ Periosteal reaction. $\mathrm{VBC}=$ Volume of bone callus. $\mathrm{QBB}=$ Quality of the bone bridge. $\mathrm{G}=$ male vs female effect evaluated by Friedman test. $\mathrm{T}=$ Placebo vs Nandrolone effect evaluated by Friedman test. $\mathrm{G} \times \mathrm{T}=$ Interaction sex and treatment effect evaluated by Kruskal-Wallis test. $\mathrm{M}=$ days effect evaluated by Kruskal-Wallis test. $\mathrm{T} \times \mathrm{M}=$ Interaction treatment and time effect evaluated by Kruskal-Wallis test. $\mathrm{G} \times$ $\mathrm{M}=$ Interaction sex and time effect evaluated by Kruskal-Wallis test. Different letters in same row indicate significant differences by Dunn's test $(\mathrm{p}<0.05)$.

Fig. 1) Median and interquartile range of periosteal reaction evaluation by sex and days of evaluation. Different letters indicate significant differences by Dunn's test $(\mathrm{P}=0.027)$. 
BMC ( $\mathrm{P}=0.0140$; Fig. 3) than the Placebo groups. There was an effect of the interaction

in females in the placebo group when compared to the other groups.

Table 2. Mean \pm SD of Bone densitometry evaluation in rabbits treated with ND versus placebo.

\begin{tabular}{|c|c|c|c|c|c|c|c|}
\hline & \multicolumn{2}{|c|}{ Placebo } & \multicolumn{2}{|c|}{ Nandrolone } & \multicolumn{3}{|c|}{ P-value } \\
\hline & Male & Female & Male & Female & G & $T$ & $\mathbf{G} \times \mathbf{T}$ \\
\hline Area, $\mathrm{cm}^{2}$ & $3.36 \pm 0.40$ & $3.68 \pm 0.45$ & $3.81 \pm 0.29$ & $3.88 \pm 0.39$ & 0.161 & 0.025 & 0.383 \\
\hline BMC, $g$ & $0.64 \pm 0.09$ & $0.61 \pm 0.09$ & $0.71 \pm 0.13$ & $0.77 \pm 0.14$ & 0.635 & 0.014 & 0.339 \\
\hline BMD, $\mathrm{g} / \mathrm{cm}^{2}$ & $0.19 \pm 0.01^{\mathrm{a}}$ & $0.16 \pm 0.01^{b}$ & $0.18 \pm 0.02^{\mathrm{a}}$ & $0.20 \pm 0.02^{\mathrm{a}}$ & 0.533 & 0.091 & 0.019 \\
\hline Area L, $\mathrm{cm}^{2}$ & $0.78 \pm 0.39$ & $0.71 \pm 0.36$ & $0.89 \pm 0.18$ & $0.74 \pm 0.44$ & 0.408 & 0.588 & 0.762 \\
\hline BMC L, g & $0.13 \pm 0.02$ & $0.09 \pm 0.01$ & $0.15 \pm 0.02$ & $0.08 \pm 0.01$ & 0.031 & 0.862 & 0.322 \\
\hline BMD L, $\mathrm{g} / \mathrm{cm}^{2}$ & $0.16 \pm 0.03$ & $0.13 \pm 0.03$ & $0.17 \pm 0.04$ & $0.13 \pm 0.06$ & 0.046 & 0.738 & 0.995 \\
\hline
\end{tabular}

161

$\mathrm{G}=$ male vs female effect. $\mathrm{T}=$ Placebo vs Nandrolone effect. $\mathrm{G} \times \mathrm{T}=$ Interaction sex and treatment effect. Different letters

Fig. 2) Mean \pm SD of Bone area in Placebo and Nandrolone groups. Different letters indicate significant differences by Tukey test $(\mathrm{P}=0.0258)$

Fig. 3) Mean \pm SD of BMC in Placebo and Nandrolone groups. Different letters indicate significant

Fig. 4) Mean \pm SD of BMC L in Male and Female groups. Different letters indicate significant differences by Tukey test $(\mathrm{P}=0.0317)$.

Fig. 5) Mean \pm SD of BMD L in Male and Female groups. Different letters indicate significant differences by Tukey test $(\mathrm{P}=0.0468)$. 
Table 3. Median \pm IQR of bone histologic evaluation in rabbits treated with ND versus placebo .

189

\begin{tabular}{|c|c|c|c|c|c|c|c|}
\hline & \multicolumn{2}{|c|}{ Placebo } & \multicolumn{2}{|c|}{ Nandrolone } & \multicolumn{3}{|c|}{ P-value } \\
\hline & Male & Female & Male & Female & G & $T$ & $G \times T$ \\
\hline $\begin{array}{l}\text { Maturation of } \\
\text { newly formed bone } \\
\text { tissue * }\end{array}$ & $4.0 \pm 0.0$ & $4.0 \pm 0.0$ & $4.0 \pm 0.0$ & $5.0 \pm 1.0$ & 0.853 & 0.902 & 0.061 \\
\hline $\begin{array}{l}\text { Extension of newly } \\
\text { formed bone tissue } \\
* *\end{array}$ & $3.0 \pm 1.0^{\mathrm{b}}$ & $5.0 \pm 2.5^{\mathrm{a}}$ & $5.0 \pm 0.0^{\mathrm{a}}$ & $5.0 \pm 2.5^{\mathrm{a}}$ & 0.334 & 0.317 & 0.043 \\
\hline $\begin{array}{l}\text { Prevalence of bone } \\
\text { tissue *** }\end{array}$ & $1.0 \pm 0.0$ & $1.0 \pm 0.25$ & $1.0 \pm 0.0$ & $2.0 \pm 1.00$ & 0.157 & 0.895 & 0.111 \\
\hline Cartilage, $\%$ & $0.0(0 / 7)^{\mathrm{b}}$ & $12.5(1 / 7)^{\mathrm{b}}$ & $62.5(5 / 8)^{\mathrm{a}}$ & $0.0(0 / 8)^{b}$ & 0.171 & 0.201 & 0.006 \\
\hline $\begin{array}{l}\text { Medullary } \\
\text { spaces, } \%\end{array}$ & $71.4(5 / 7)$ & $50.0(4 / 8)$ & $37.5(3 / 8)$ & $62.5(5 / 8)$ & 0.285 & 0.855 & 0.569 \\
\hline
\end{tabular}
sex and treatment effect evaluated by Kruskal-Wallis test. Different letters in same row indicate significant differences by Dunn's test $(\mathrm{p}<0.05) .{ }^{*}=$ evaluated according to the scale where $0=$ no periosteal reaction, $1=$ moderate periosteal response, $2=$ intense periosteal response, 3 = disorganized newly formed bone tissue, $4=$ Newly formed bone tissue with moderate organization, and $5=$ tissue bone formation with advanced organization. $* *=$ assessed according to a scale where $0=$ no new bone formation or it was not possible to assess, 1 = mild bone formation, $2=$ mild / moderate bone formation, $3=$ moderate bone formation, $4=$ moderate / intense bone formation, and $5=$ intense new bone formation. $* * *=$ assessed according to the scale where $1=$ prevalence of primary bone tissue, and $2=$ prevalence of secondary bone tissue.

region of the osteotomy, was similar to a normal medullary canal in a few animals.

205

206

207

208

209

210

211

Fig 6: Female Nandrolone 3 - new bone formation at 90 days. There are parallel lamellae arranged on concentric circles around the Haversian canals (mature or secondary bone). HE, 40x lens.

Discrete focal areas of primary bone tissue were observed in most males in the placebo group and focal areas of primary bone tissue, sometimes with fibrocartilage, in the nandrolone group.

\section{DISCUSSION}

There is little published information on the effect of ND on bone healing in experimental and clinical veterinary patients, especially those with nonunion. This study describes some benefits of the use of ND for bone regeneration at the site of critical-size radial defects in rabbits. 
Previous studies have successfully demonstrated complete filling of bone defects in animals receiving ND, which confirms the acceleration of bone consolidation (5); however, in these studies non-critical circular bone failures of up to $4 \mathrm{~mm}$ in diameter were used. It is believed that the experimental failure model used in this study more accurately simulates atrophic bone nonunions. Although complete healing was not achieved in this study the efficacy of the drug in the formation of bone tissue was more effectively evaluated.

In previous studies on ND in guinea pigs, its effectiveness in bone activity was observed; however, these studies are limited because they were evaluated qualitatively. In this study, the evaluations were scored to achieve greater accuracy and reliability of the results $(5,7)$. androgenic therapies might be affected by the physiological and hormonal differences between the sexes. The results obtained in this study suggest that the level of serum circulating testosterone in males may positively affect bone regeneration capacity. There are few reports on this subject in the literature. Previous studies have not demonstrated significant differences between the sexes in young animals (11). Future studies should evaluate the aforementioned parameters and correlate them with the capacity for osteogenesis.

A study by Li et al (12) evaluated the effectiveness of ND against bone loss as an androgenic agent, comparing the use of ND in ovariectomized rats This demonstrated a greater $\mathrm{BMD}$ in the evaluated bones in the treated group. In the general densitometric analysis, the

241 female placebo group had lower BMD. This result confirms the effectiveness of ND and 242 suggests that androgens are essential for optimal bone healing. 
The same finding was observed in studies that involved osteoporotic women treated

with ND. In another study, men showed a 50\% increase in the risk of pathological fractures

who had not undergone the procedure. No decrease in BMD on bone densitometry was seen in men who received androgen therapy in contrast to untreated men $(13,14)$.

The animals in the nandrolone group showed a greater BMC then the placebo group.

Flicker et al. (15) observed a significant increase in bone mineral content in osteopenic females

Guimarães et al. (16) evaluated the influence of ND on bone quality through the evaluation of

BMD in male rats after 28 days of treatment and found no significant differences between the quality from the thirtieth day of treatment.

The microscopic findings showed that the animals in placebo groups had a predominance of primary bone tissue. On the other hand, lamellar organizations of secondary bone and the presence of fibrocartilage were observed in the treated groups. Recently, Senos et al. and Ahmad et al. $(17,7)$ administered ND for fractures of the femur and mandible in rabbits, and they observed an increase in bone mass, regular bone surface, and reduction in the time to bone regeneration. These results may indicate that ND facilitates osteogenic activity and can accelerate the stages of bone healing.

The degree of fibrocartilaginous tissue formation was different for males and females. concentrations and contribute to greater periosteal bone formation and, therefore, greater bone

267 dimensions $(13,18)$. This is corroborated in this study by the higher percentage of 
fibrocartilaginous tissue in the NMG. The extent of direct interaction between androgens and osteoblasts or their precursors is still unclear. Androgens affect skeletal growth, including the increase in vascular and muscle cell activity (13).

In this study, treatment with ND resulted in improvement in bone healing in nonunion

272 fractures. However, complete healing did not occur in the NG or PG, as expected, due to the restricted duration of the study. The most important limitation in this study was the inability to assess the side effects of ND, as several studies have shown that the androgen overdose associated with long-term treatment is associated with systemic changes (19-20). Although we did not specifically investigate potential side effects, the animals remained healthy throughout the evaluation. Further studies using ND for a longer period in cases of nonunion of fractures are recommended to assess long-term side effects and the prolonged effect of ND on bone regeneration.

Treatment with ND produced an increase in bone regeneration after the creation of a large defect in the tibia of rabbits. However, this therapy must be combined with surgical treatment, such as fracture fixation and the use of autologous grafts.

\section{ACKNOWLEDGEMENTS}

We thank Professor Dr. Alan Rodrigo Panosso, from the Department of Engineering and Exact Sciences for performing the statistical analyses of this study. We also thank Professor Dra. Silvana Martinez Baraldi Artoni and Professor Dra Lizandra Amoroso from the Department of Animal Morphology and Physiology, who allowed bone densitometry examinations. We are also grateful to CAPES for the funding and support of this research. 
1. Tsai KL. Case report: three cases of non-union fracture in dogs treated with adipose-derived adult stem cells combined with autologous cancellous bone and synthetic bone substitutes. Taiwan Veterinary Journal 2017 Jan 19;43(1):1-9. on healing of experimentally induced critical-sized radial bone defects in rabbits (oryctolagus cuniculus)" outcome of nonunion fractures in dogs treated with fixation, compression resistant matrix, and recombinant human bone morphogenetic protein-2. Vet Comp Orthop Traumatol. 2017 Jan 17;30:153-159.

3. Dinopoulos H, Giannoudis PV. The use of bone morphogenetic proteins (BMPs) in longbone non-unions. Current Orthopaedics. 2007;21:268-279. Veterinary surgery: small animal. Missouri: Elsevier Saunders 1 (2012): 647-656. tibial bone defect healing in rabbit. Euro. J. Exp. Bio. 2012;2:1315-1319. of nandrolone decanoate on time to consolidation of bone defects resulting from osteotomy for tibial tuberosity advancement. Vet Comp Orthop Traumatol. 2017;30: 351-356. healing in rabbits-a study on experimental model. Journal of Clinical and Diagnostic Research:

311 JCDR 2013 Jan 1;7(1):93-96.

312 8. An YH, Friedman RJ, Draughn, RA. Animal Models of Bone Fracture or Osteotomy.

313 Animal models in orthopaedic research. Boca Raton: CRC Press; 1999:197-217. 
315 phytoestrogensoestrogens on fracture healing: experimental research in New Zealand white

316 rabbits. Ulus Travma Acil Cerrahi Derg. 2008 Jan;14:21-27.

317 10. Balthazar DA, Silva MFA, Castro DS, Suzano SMC, Cruz RA . Effect of cortico318 cancellous bone grafting in osteogenesis of cortical ulnar failure of domestic chickens (Gallus 319 domesticus). Arq. Bras. Med. Vet. Zootec 2013;65:119-126.

320 11. Miranda ES, Cardoso FTS, Medeiros-Filho JF, Barreto MDR, Teixeira RMM, Wanderley 321 AR, et al. Organic and inorganic bone graft use in rabbit's radius surgical fractures repair: an experimental and comparative study. Acta Ortop Bras, 2005;13(5):245-248. nandrolone decanoate on bone mass and metabolism in ovariectomized rats with osteopenia. $\mathrm{J}$ Bone Miner Metab 2000 Jan 28; 18:258-263.

13. Vanderschueren D, Vandenput L, Boonen S, Lindberg MK, Bouillon R, Ohlsson C. 327 Androgens and bone. Endocr Rev 2004 Jun;25(3):389-425. supplementation and nandrolone on bone tissue after a hip fracture. Clinical Nutrition, 2007;26:460-465. decanoate and intranasal calcitonin as therapy in established osteoporosis. Osteoporosis Int, 
337 17.Senos R, Roberto-Rodrigues M, Fernandes RMP, Santos TMP, Viana LP, Lima I, et al.

338 Nandrolone decanoate in induced fracture nonunion with vascular deficit in rat model:

339 morphological aspects. Musculoskeletal Surgery 2019 Aug 12;1-9.

341 18. Ahlborg HG, Johnell O, Turner CH, Rannevik G, Karlsson MK. Bone loss and bone size

342 after menopause. N. Engl J Med 2003 Jul 24;349(4):327-334.

343 19. Melloni RH, Connor DF, Hang PTX, Harrison RJ, Ferris CF. Anabolic-androgenic steroid

344 exposure during adolescence and aggressive behavior in golden hamsters. Physiology \&

345 Behavior, 1997;61(3) 359-364.

346 20. Pozzi R, Fernandes KR, Moura CFG, Ferrari RAM, Fernandes KPS, Renno ACM, et al.

347 Nandrolone Decanoate Induces Genetic Damage in Multiple Organs of Rats. Arch Environ

348 Contam Toxicol, 2013;64:514-518. 


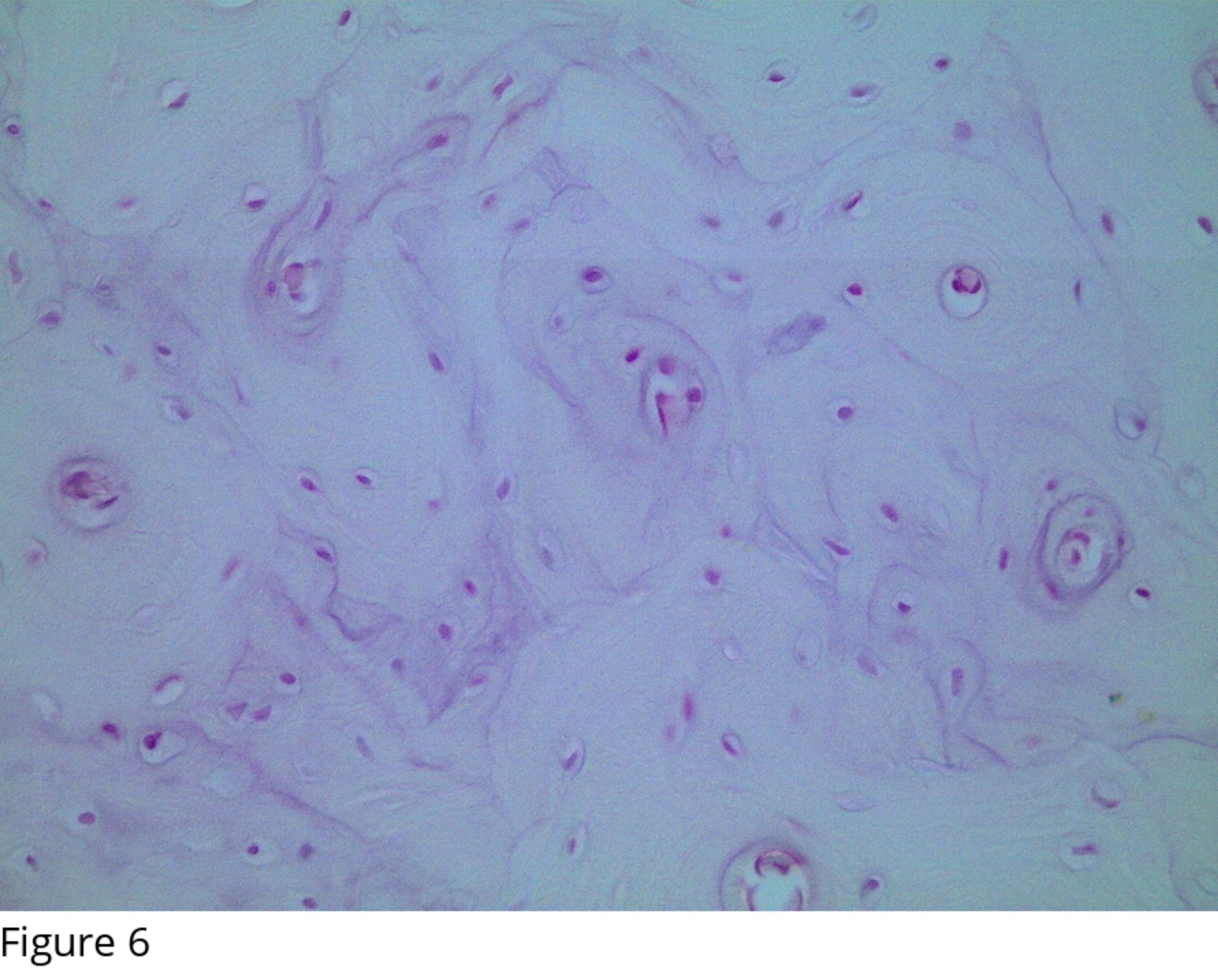




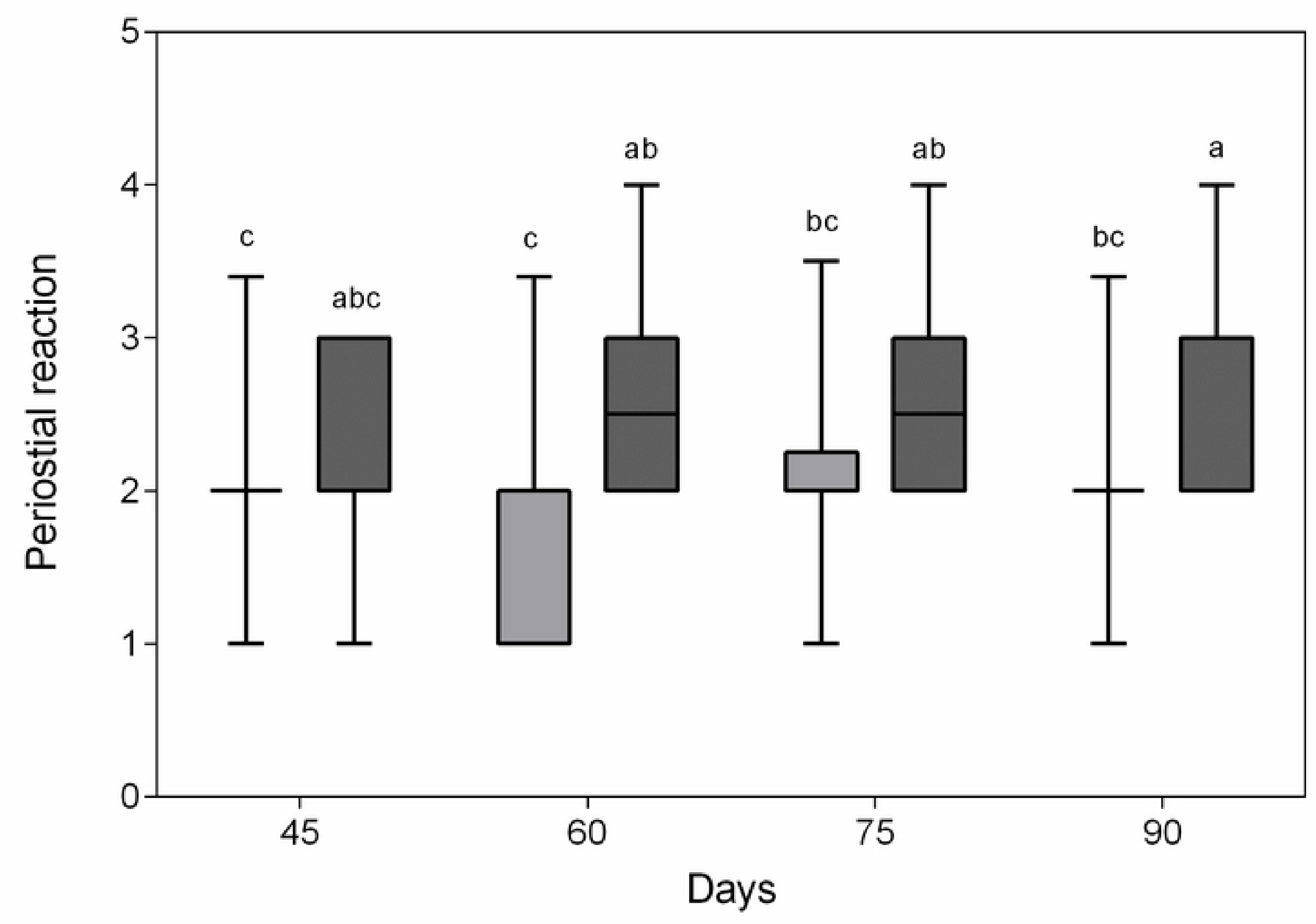

$\square$ MALE

$\square$ FEMALE

Figure 1 


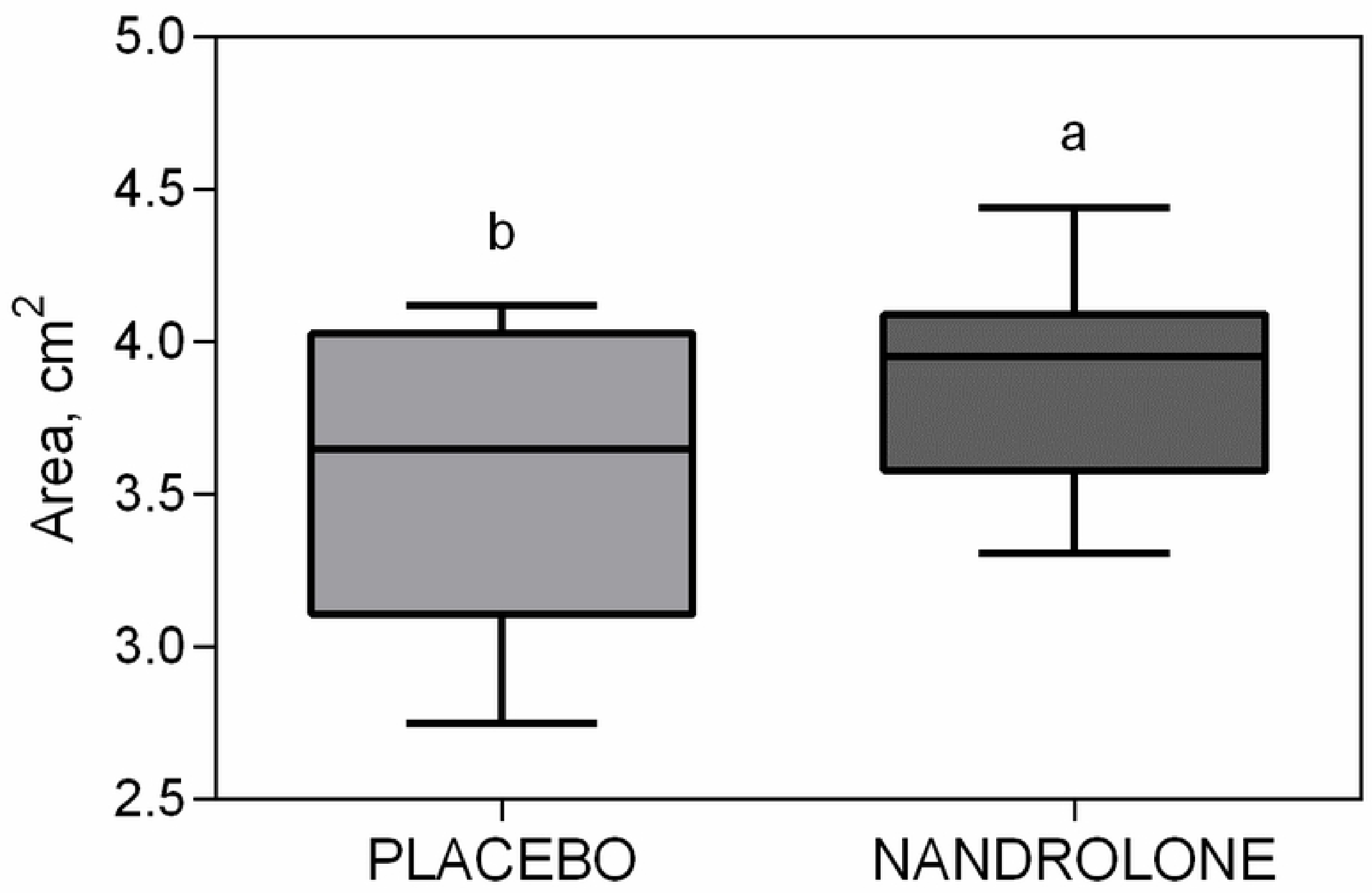

Figure 2 


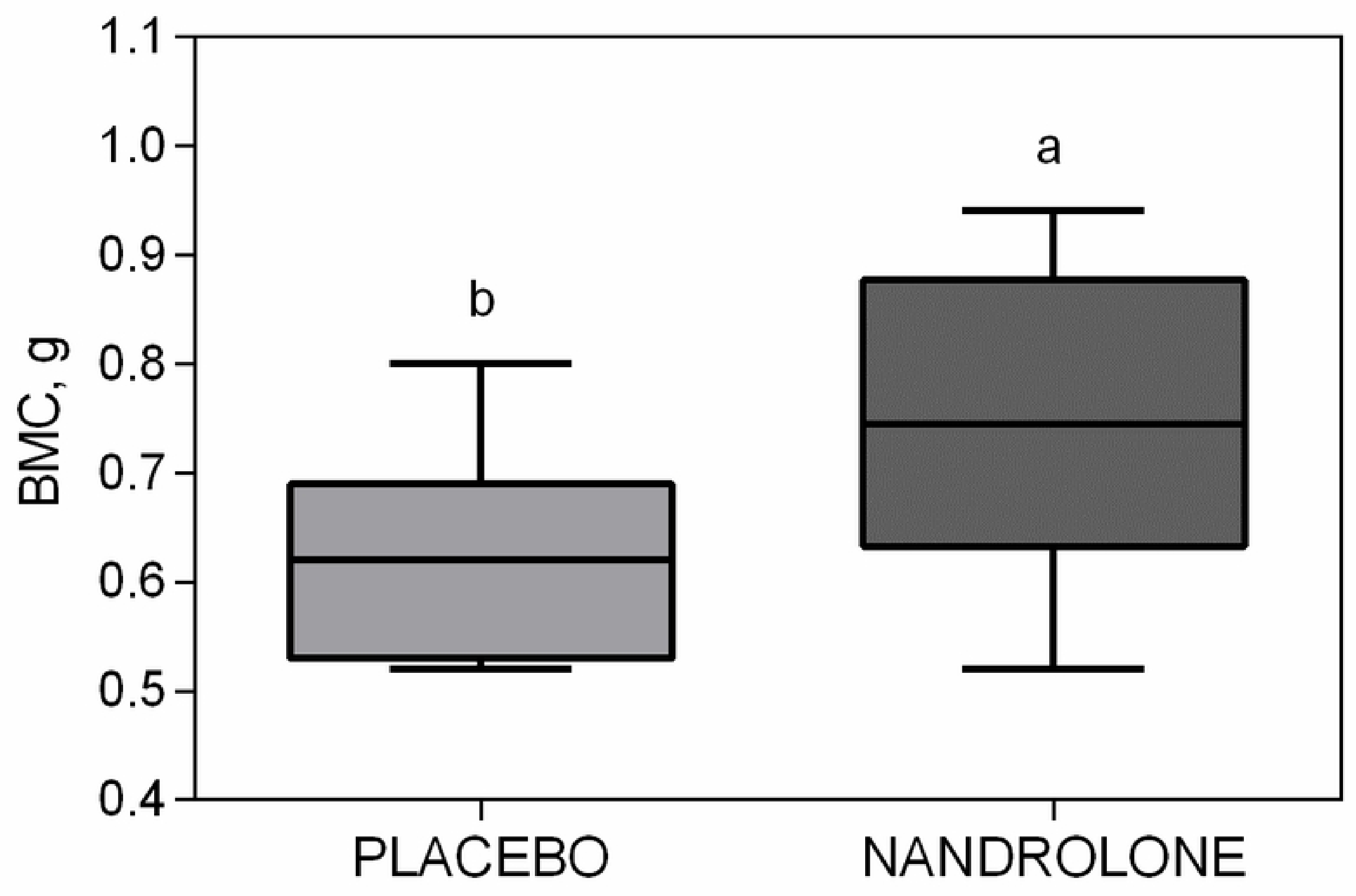

Figure 3 


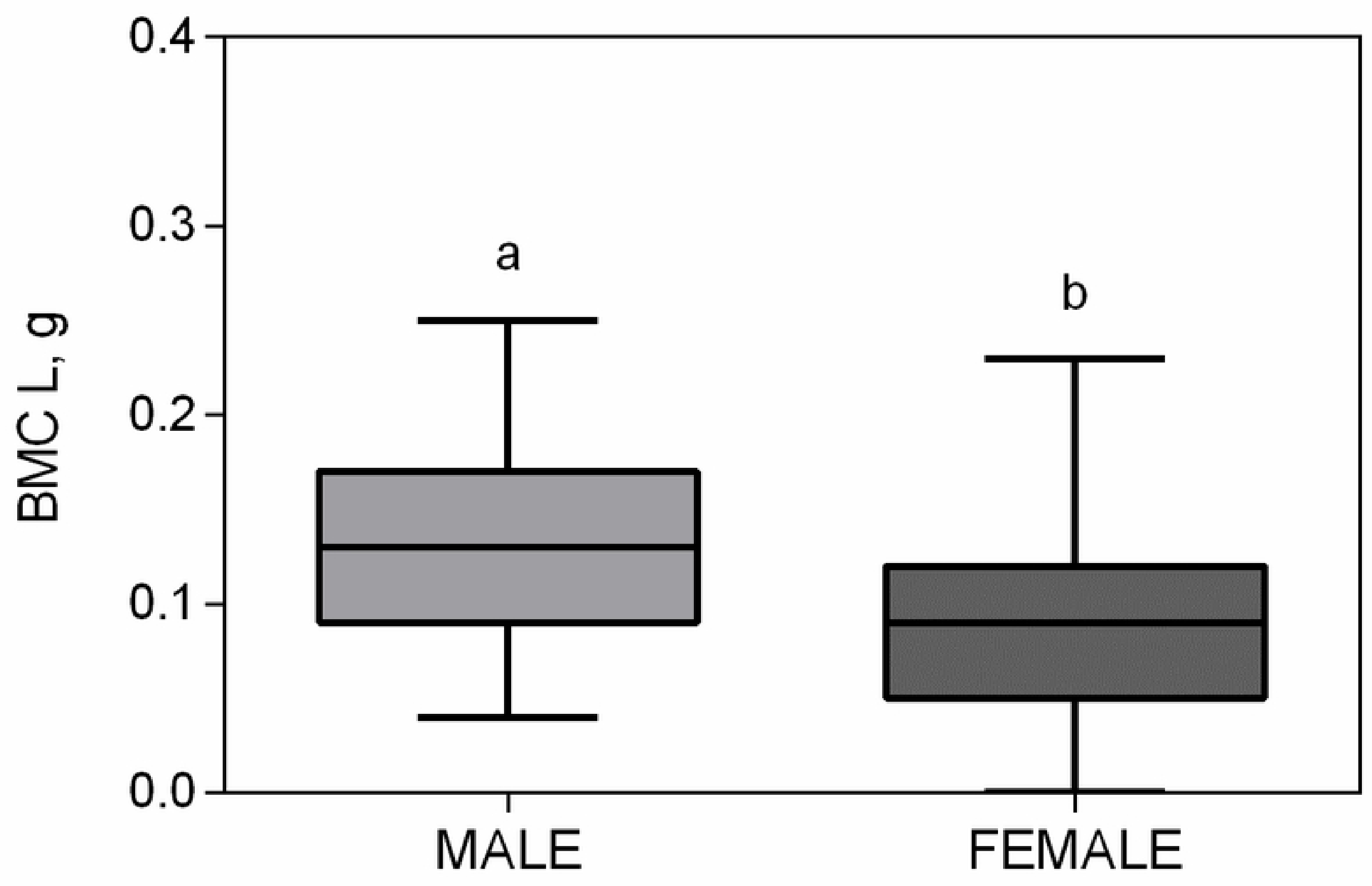

Figure 4 


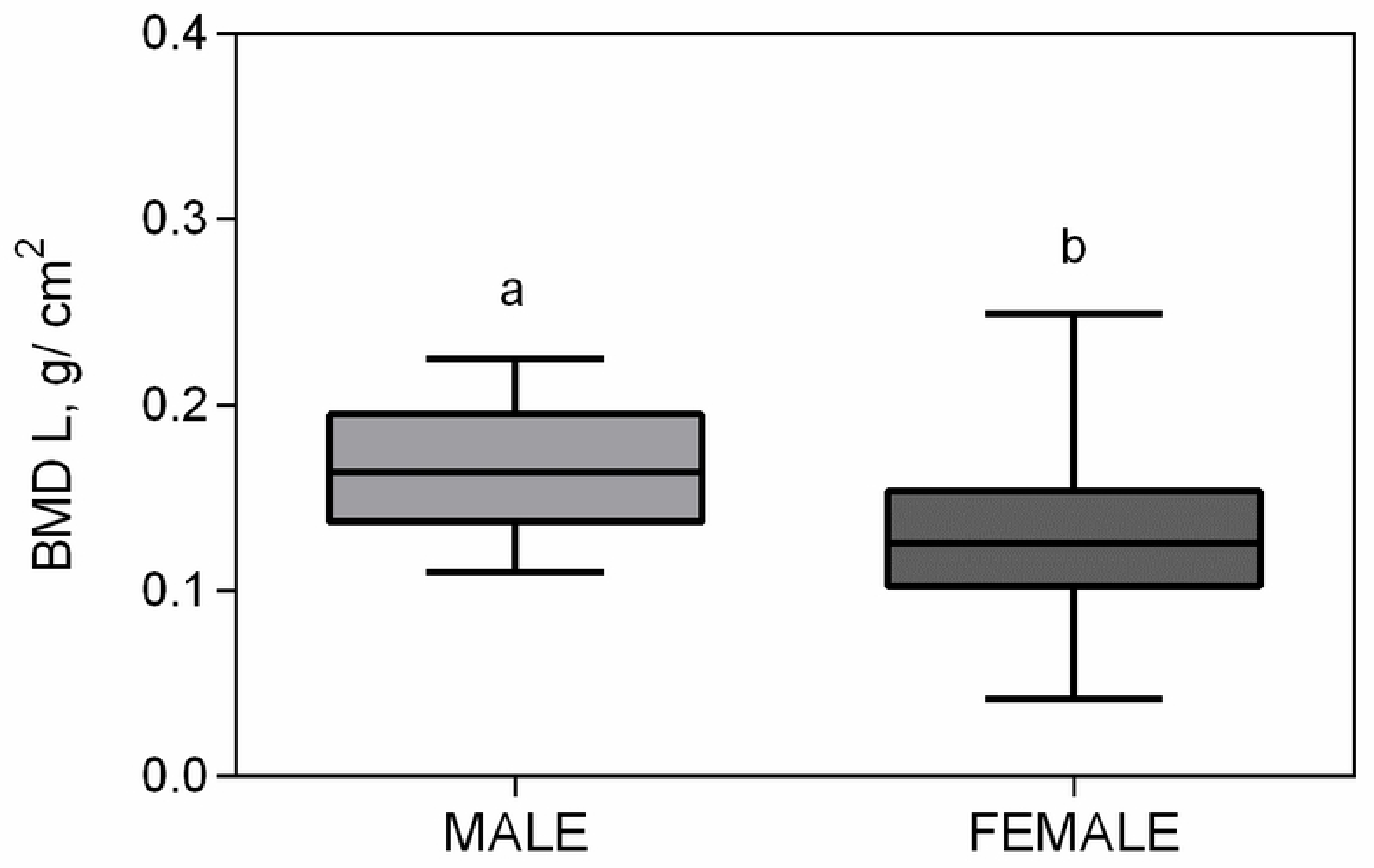

Figure 5 